Journal of Social Sciences 4 (1): 21-28, 2008

ISSN 1549-3652

(C) 2008 Science Publications

\title{
Effects of Training on Skill Development of Agricultural Extension Workers in Bangladesh: A Case Study in Four Upazilas (Sub-district) Under Kishoreganj District
}

\author{
${ }^{1}$ Mohammad Jiaul Hoque and ${ }^{2}$ Koichi Usami \\ ${ }^{1}$ The United Graduate School of Agricultural Sciences, Tottori University, Tottori, Japan \\ ${ }^{2}$ Faculty of Agriculture, Yamaguchi University, Yamaguchi, Japan
}

\begin{abstract}
This study was conducted to identify the contributing Off-the-Job Trainings (Off-JT) and determinant On-the-Job Training (OJT) for developing Agricultural Extension Workers' (AEWs) extension skills. Data on AEWs' skill levels on selected four extension skill areas (namely, working with group, organizing and running a demonstration, assessing farmers' problems, and work planning), attendance of Off-JT, and OJT practices were collected from 90 AEWs using structured questionnaires. The mean scores of AEWs' extension skill levels on the four extension skill areas ranged from 60 to 67. Most of the Off-JTs significantly differed between the AEWs' group 1 (namely the low skill level group) and AEWs' group 2 (namely the high skill level group) in the areas of selected four extension skills. Except one Off-JT on "developing group dynamics" all the others OffJTs were important contributing factors to the AEWs' skill on working with group. Less than half of the Off-JTs were important contributing factors to the AEWs' skill on organizing and running a demonstration, problem identification, and planning. On the other hand, almost all of the AEWs in group 2 were practiced OJT with intension to develop their extension skills. However, the OJT that practiced by the AEWs in group 1 was very much limited.
\end{abstract}

Key words: Agricultural Extension Worker, Off-the-Job Training, On-the-Job Training, Extension Skill, Department of Agricultural Extension, Bangladesh

\section{INTRODUCTION}

The Department of Agricultural Extension (DAE) is the largest government organization in Bangladesh, which provides unified agricultural extension services to farmers throughout the country. To provide high quality agricultural extension services, the DAE employs 12,640 agricultural extension workers (AEWs) at the field level ${ }^{[9]}$. According to the DAE guidelines, each AEW has to provide agricultural extension services to around 1,200 farm households in his/her service upazila (sub-district) ${ }^{[8]}$. Due to the extensive coverage of each AEW, the success in agricultural extension services largely depends on AEWs' extension skills. As a matter of fact, however, only $13.93 \%$ of the AEWs are credible as communicator of technical advice to farmers ${ }^{[14]}$. Furthermore, $35 \%$ of farm information loss has been found to take place in the transit between AEWs and farmers although AEWs regularly attend off-the-job training (hereinafter OffJT ${ }^{[4]}$. Due to lack of extension skills AEWs are not able to provide satisfactory extension services to farmers ${ }^{[1]}$. Lack of AEWs' extension skills result in less adoption of improved rice variety by the farmers ${ }^{[11]}$.
In the context of extension skill development, training is a common constraint for developing AEWs' extension skills in Bangladesh ${ }^{[10]}$. It was reported that neither the simple number of in-service training nor the simple duration of in-service training in the total service period could improve the job performance of the Agricultural Extension Officers in Bangladesh ${ }^{[15]}$. In spite of having immense importance of training, AEWs are not getting proper training due to i) no specific training plan, ii) inadequate training resources and facilities, and iii) less cooperation and coordination amongst extension providers ${ }^{[1]}$. Off-JT is often not the most effective or cost effective way to develop AEWs' extension skills ${ }^{[7]}$. Meanwhile, in the current training policy, despite of the demand for quality skill, "costless/less cost" or "cost effectiveness" has been emphasized under the fund shortage for training programs. Though being not materialized enough, onthe-job training (hereinafter OJT) is introduced as a symbolic term for skill development in training policy.

Nowadays, all of the AEWs are encouraged to develop their own abilities through practicing OJT along with attending Off-JT. In order to develop extension skills of AEWs with maximizing the use of limited resources of the DAE, it is an inevitable task to

Corresponding Author: Mohammad Jiaul Hoque, Department of Agricultural Extension Education, Bangladesh Agricultural University, Mymensingh - 2202, Bangladesh, Tel: (88091) 55695, Fax: (88091) 55810 
review the current Off-JT and enhance the OJT with concreteness. So far, numerous related studies have cited problems with the Off-JT in Bangladesh. Besides, the present condition of OJT practices by AEWs is hardly known in Bangladesh. Therefore, toward facilitating in decision making for training designer as well as policy makers to revise the current training program for AEWs, the present study aims at identifying the comparatively high contributing Off-JTs and the determinant OJT practices to AEWs' extension skill levels.

\section{MATERIALS AND METHODS}

The target population for this study consisted of all the AEWs (total 236) in Kishorganj district. Out of 13 upazilas (sub-district) in this district 4 upazilas, namely Hossainpur, Pakundia, Kotiadi, and Kishorganj were purposively selected for this study. Upazila-based random sample of AEWs (101) in four randomly selected upazilas was identified. According to the Agricultural Extension Manual ${ }^{[7]}$, the present study adopted four extension skill areas such as (i) working with group, (ii) organizing and running a demonstration, (iii) assessing farmers' problems, and (iv) work planning from the annual competence assessment form for extension staff development. The data were collected by using designed standard questionnaire from effective 90 Agricultural Extension Workers (AEWs) (due to $11 \mathrm{AEWs}$ on personal leave) during April to May 2006 and resulted in a 100 percent response rate. The questionnaire consisted of four parts. The first part included the AEWs' selected characteristics such as age, service tenure, and educational level. The second part was on measuring AEWs' extension skill levels. Skill levels of an AEW were evaluated by 3 Upazila Agricultural Officers (UAO) who supervised his/her daily activities, 3 skillful AEWs senior to him/her, and 3 farmers from the area in his/her charge. UAOs and senior AEWs always remain close contact with AEWs. Each UAO and AEW were directly asked to evaluate the skill levels of all AEWs in the assigned upazila from 0 point to 100 point using the following criteria: AEWs who can provide proper extension services to farmers will be given 100 point and who cannot provide satisfactory extension service at all will be given 0 point. Meanwhile, farmers are not aware of all AEWs in a upazila, and so 3 farmers in a block were asked to evaluate the AEW assigned to their block in accordance to the basic criteria: encouraging farmers to talk to about their problem; learning from farmers; building the confidence of farmers; discussing ideas and sharing options openly with farmers; assisting farmers to undertake their own planning; and providing solution to the farmers' problems. Thus, though an AEW can be evaluated by 9 persons separately, the level of an extension skill for analysis was calculated as an average of all scores of the three types of evaluators. The third part of the questionnaire included AEWs' attendance to Off-JT (measured by days) during 20012005, and the final section consisted of AEWs' OJT practices (yes or no). Especially, data on OJT practices were collected through intensive interviews with the AEWs.

A pilot-test with 12 AEWs was conducted in the study area before fielding the study and accordingly minor changes were made in the questionnaire. Descriptive statistics such as frequencies, percentages, means, and standard deviations were used to analyze the data. To examine the qualitative relationship between Off-JT or OJT and skill levels, first the AEWs were grouped into those (Group 1: the low skill level group) whose skill level was less than the average and those (Group 2: the high skill level group) whose skill level was higher than the average. T-tests and analysis of variance (ANOVA) were used to determine whether there were significant differences between AEWs' groups with regard to their extension skill levels, attendance of Off-JT, and OJT practices. Furthermore, from the viewpoint of quantitative relationship, the multiple linear regression analysis was used to identify the comparatively high effective Off-JTs to the AEWs' extension skill levels. As OJT practices could not be measured quantitatively, the discriminant analysis was used to identify determinant OJT practices to the AEWs' extension skill levels.

\section{RESULTS AND DISCUSSION}

Characteristics of Agricultural Extension Workers (AEWs): A higher proportion (59\%) of the AEWs were between 41 and 50 years of age with an average of 46.30 years. The AEWs had on average 23 years of service tenure as an AEW. There was no respondent whose service tenure was less than 10 years. All of them gained "Agricultural Diploma" as an associate degree from the Agricultural Training Institutes. However, the $44 \%$ of the AEWs had a Higher Secondary Certificate (HSC) degree, the 36\% a Secondary School Certificate (SSC) degree, and only $12 \%$ a Bachelor of Science degree.

Agricultural Extension Skill Levels of AEWs: As shown in Table 1, the scores of the four extension skill levels ranged from 36 to 86 (range of mean $=60$ to 67), with comparatively large differences among the AEWs. Comparing such differences among the AEWs, that among the four extension skills was small. The levels of skills related to extension activities in the field like the former three extension skills were comparatively high. Mean value of extension skill levels of AEWs' group 2 was very much higher than that of AEWs' group 1 and the differences were statistically significant at $1 \%$ significance level (Table 2). 
Table 1. State of AEWs' skill levels in the study area (range of score: 0-100)

\begin{tabular}{lccc}
\hline \multicolumn{1}{c}{ Skill } & Observed Range (score) & Mean (score) & Standard deviation \\
\hline 1. Working with group & $46-84$ & 67 & 8.93 \\
2. Organizing and running a demonstration & $43-83$ & 66 & 7.85 \\
3. Assessing farmers' problem & $43-86$ & 64 & 8.81 \\
4. Work planning & $36-83$ & 60 & 9.19 \\
\hline
\end{tabular}

Source: Authors' survey (2006).

Table 2: Comparisons of extension skill levels of AEWs' group 1 and AEWs' group 2

\begin{tabular}{lrrc}
\multicolumn{1}{c}{ Skills } & AEWs' group 1 $1^{\mathrm{a}}$ (Mean) & AEWs' group 2 ${ }^{\mathrm{b}}($ Mean $)$ & t-statistic \\
\hline 1. Working with group & 59.83 & 73.95 & $-12.306^{* * *}$ \\
2. Organizing and running a demonstration & 60.87 & 71.23 & $-8.312^{* * *}$ \\
3. Assessing farmers' problem & 56.83 & 70.48 & $-11.649^{* * *}$ \\
4. Work planning & 53.74 & 65.84 & $-8.366^{* * *}$
\end{tabular}

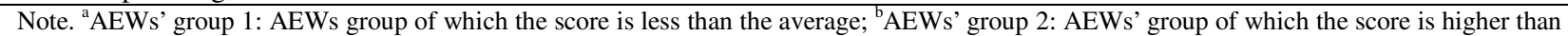
the average; ***: Significant difference in the means between group 1 and group 2 at the level of $1 \%$.

Source: Authors' survey (2006)

Table 3. Comparison of off-jt attendance of AEWs' group 1 and AEWs' group 2 (2001-2005)

\begin{tabular}{|c|c|c|c|c|}
\hline \multirow[t]{2}{*}{ Skills } & \multirow{2}{*}{$\begin{array}{c}\text { Training } \\
\text { (Unit: days) }\end{array}$} & \multirow{2}{*}{$\frac{\text { AEWs' group } 1^{\mathrm{a}}}{\text { Mean }}$} & \multirow{2}{*}{ 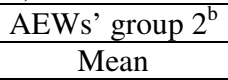 } & \multirow[t]{2}{*}{ t- value } \\
\hline & & & & \\
\hline \multirow{6}{*}{$\begin{array}{l}\text { Working with } \\
\text { group }\end{array}$} & Group formation & $6.67(1.70)^{\mathrm{c}}$ & $11.02(2.28)$ & $-10.29 * * *$ \\
\hline & Group management & $9.74(1.39)$ & $10.18(1.40)$ & -1.504 \\
\hline & Leadership development & $10.76(.77)$ & $13.25(1.05)$ & $-13.18 * * *$ \\
\hline & Problem identification & $10.98(1.63)$ & $14.14(.75)$ & $-11.89 * * *$ \\
\hline & Development of group members' skills & $6.67(1.25)$ & $9.16(.86)$ & $-10.95 * * *$ \\
\hline & Development of group dynamics & $8.04(10.60)$ & $9.32(.77)$ & -0.79 \\
\hline \multirow{7}{*}{$\begin{array}{l}\text { Organizing and } \\
\text { running a } \\
\text { demonstration }\end{array}$} & Determine objectives & $19.64(5.08)$ & $21.42(3.06)$ & $-2.010 * *$ \\
\hline & Selection of place & $18.38(3.45)$ & $24.24(2.12)$ & $-9.709 * * *$ \\
\hline & Encourage participants & $16.33(3.62)$ & $22.33(2.20)$ & $-9.511 * * *$ \\
\hline & Input management & $15.98(3.99)$ & $23.20(2.87)$ & $-9.870 * * *$ \\
\hline & Technical support to farmers & $10.27(1.34)$ & $14.40(2.04)$ & $-11.371 * * *$ \\
\hline & Monitoring and evaluation & $16.38(2.89)$ & $21.80(2.89)$ & $-8.895^{* * *}$ \\
\hline & Planning activities after demonstration & $15.58(1.98)$ & $15.40(1.94)$ & 0.430 \\
\hline \multirow{5}{*}{$\begin{array}{l}\text { Assessing } \\
\text { farmers' } \\
\text { problems }\end{array}$} & Identify the problems & $10.90(.93)$ & $14.81(1.73)$ & $-13.612 * * *$ \\
\hline & Analyze the problems & $9.33(1.12)$ & $13.38(2.63)$ & $-9.709 * * *$ \\
\hline & Development of group dynamics & $12.88(2.75)$ & $17.86(1.92)$ & $-9.830 * * *$ \\
\hline & Uses resource person & $9.63(1.61)$ & $13.67(1.57)$ & $-12.028 * * *$ \\
\hline & Making good rapport with farmers & $9.35(.73)$ & $14.52(2.19)$ & $-25.423 * * *$ \\
\hline \multirow{5}{*}{ Work planning } & Determine objectives & $4.74(.85)$ & $6.40(1.25)$ & $-7.325^{* * *}$ \\
\hline & Select suitable time and workplace & $4.12(.39)$ & $6.94(1.77)$ & $-10.193 * * *$ \\
\hline & Select farmers' group & $11.21(1.37)$ & $14.02(1.11)$ & $-10.715^{* * *}$ \\
\hline & Use of necessary inputs & $3.95(.65)$ & $5.57(1.56)$ & $-7.506^{* * *}$ \\
\hline & Use of resource person & $11.09(1.17)$ & $13.96(.20)$ & $-16.502 * * *$ \\
\hline
\end{tabular}

Note. ${ }^{a} \mathrm{AEWs}$ ' group 1: AEWs group of which the score is less than the average; ${ }^{\mathrm{b}} \mathrm{AEWs}$ ' group 2: AEWs' group of which the score is higher than the average; **: Significant difference in the means between Group 1 and Group 2 at the level of 5\%; ***: Significant difference in the means between Group 1 and Group 2 at the level of $1 \%$; ${ }^{\circ}$ Values in the parenthesis are SD.

Source: Authors' survey (2006)

Off-JT Attendance and Extension Skill Levels: Table 3 shows the result of statistical test on whether or not there is a significant difference in Off-JT attendance in the past 5 years (2001-2005) between the two groups defined above relating to the average skill level. As there was no respondent whose service tenure was below 10 years, the Off-JT participated by the AEWs in the areas of four extension skills were in-service training as well as periodic trainings. In terms of training days and variation, the skill 4 (work planning) was inferior to the others. Besides, the imbalances in training days among the trainings were comparatively 
remarkable in the skill 4 (work planning). Excluding several training, regardless of extension skills as well as trainings, there was a statistically significant differences in training days between the low skill level group (group 1) and the high skill level group (group 2). It can be seen that the more training they attend, the higher the extension skill level is.

Off-JT Contributing to Extension Skill Levels: The result of multiple linear regression analysis on the quantitative relation between attendance of Off-JTs and extension skill level is presented in Table 4. According to adjusted $\mathrm{R}^{2}$ and $\mathrm{F}$-value, each of the estimations was reasonable. Off-JTs regarding group formation, group management, leadership development, problem identification, and development of group members' skill were important contributing Off-JTs to the development of AEWs' skill levels on working with group. Among these trainings, problem identification showed highest effect on AEWs' skill levels about working with group. This is because only identifying appropriate problem could enable AEWs for working with group successfully. Off-JT about selection of place, technical support to farmers, and monitoring and evaluation were important contributing Off-JTs to the development of AEWs' skill levels on organizing and running a demonstration. As expected, Off-JT about selection of place for demonstration showed the highest effect on the development of AEWs' demonstration skill level. Two types of Off-JTs regarding identifying problems, development of group dynamics, and use of resource persons were contributing trainings to the development of AEWs' skill levels on assessing farmers' problems. Off-JTs on selecting suitable time and work place and use of resource person were important contributing Off-JTs to the development of AEWs' skill levels on work planning.

OJT Practices and Skill Levels: Table 5 shows the present types of OJT practices and the comparison in the percentage of AEWs practicing OJTs between the two groups, namely the low skill level AEWs (group 1) and the high skill level AEWs (group 2). Almost all of the AEWs in group 2, practiced all of the OJTs in order to develop their extension skill levels. In contrast, the OJT that the AEWs in group 1 practiced was remarkably limited, namely single OJT.

Table 4. Result of regression analysis on contributing Off-JT for AEWs' extension skill levels (Sample size 89)

\begin{tabular}{|c|c|c|c|c|c|}
\hline Skills & Training & Coefficient & Constant value & Adjusted $\mathrm{R}^{2}$ & F-value \\
\hline \multirow{6}{*}{$\begin{array}{l}\text { Working } \\
\text { with group }\end{array}$} & Group formation & $0.228 * *$ & \multirow{6}{*}{9.09} & \multirow{6}{*}{0.97} & \multirow{6}{*}{$\begin{array}{c}408.48 * * \\
(6,83)\end{array}$} \\
\hline & Group management & $0.351 * *$ & & & \\
\hline & Leadership development & $0.992 * * *$ & & & \\
\hline & Problem identification & $2.404 * * *$ & & & \\
\hline & Development of group members' skills & $1.250 * * *$ & & & \\
\hline & Development of group dynamics & 0.031 & & & \\
\hline \multirow{7}{*}{$\begin{array}{l}\text { Organizing and } \\
\text { running a } \\
\text { demonstration }\end{array}$} & Determine objectives & -0.001 & \multirow{7}{*}{28.56} & \multirow{7}{*}{0.94} & \multirow{7}{*}{$\begin{array}{c}211.85 * * x \\
(7,82)\end{array}$} \\
\hline & Selection of place & $1.238 * * *$ & & & \\
\hline & Encourage participants & -0.243 & & & \\
\hline & Input management & 0.321 & & & \\
\hline & Technical support to farmers & $1.144 * * *$ & & & \\
\hline & Monitoring and evaluation & $-0.259 * * *$ & & & \\
\hline & Planning activities after demonstration & 0.018 & & & \\
\hline \multirow{5}{*}{$\begin{array}{l}\text { Assessing } \\
\text { farmers' } \\
\text { problems }\end{array}$} & Identify the problems & $1.174 * * *$ & \multirow{5}{*}{22.79} & \multirow{5}{*}{0.90} & \multirow{5}{*}{$\begin{array}{c}153.12 * * \\
(5,84)\end{array}$} \\
\hline & Analyze the problems & 0.514 & & & \\
\hline & Development of group dynamics & $0.622 * *$ & & & \\
\hline & Uses resource person & $0.471 * *$ & & & \\
\hline & Making good rapport with farmers & 0.480 & & & \\
\hline \multirow{6}{*}{ Work planning } & Determine objectives & -0.503 & \multirow{6}{*}{12.48} & \multirow{6}{*}{0.83} & \multirow{6}{*}{$\begin{array}{c}85.98 * * * \\
(5,84)\end{array}$} \\
\hline & Select suitable time and work place & $2.343 * * *$ & & & \\
\hline & Select farmers' group & -0.125 & & & \\
\hline & Use of necessary inputs & 0.307 & & & \\
\hline & Use of resource person & $2.936 * * *$ & & & \\
\hline & Select methods of monitoring & $1.820 * *$ & & & \\
\hline
\end{tabular}

Note. **: Significant at the level of 5\%; ***: Significant at the level of $1 \%$.

Source: Authors'survey (2006) 
The OJTs comparatively common to both of the two groups, namely regardless of extension skill level, were as follows: (i) Working with group: forming new group under close supervision of Agricultural Extension Officers (AEO); (ii) Organizing and running a demonstration: none; (iii) Assessing farmers' problems: assessing farmers' problems with the close supervision of AEO, and (iv) Work planning: preparing work plan with close supervision of AEO.

\section{Determinant of OJT Practices to Extension Skill Levels \\ A Case of Skill on Working with Group: Out of 90 cases used in the discriminant analysis, 46 cases belonged to the group 1 (namely the low skill level group) and 44 cases to the group 2 (namely the high skill level group). The mean discriminant score (centroid) for the group $1(-2.45)$ was significantly different that for the group 2 (2.56). According to the estimated discriminant function, an overall correct classification rate was $94.4 \%(95.7 \%$ for the group 1}

and $93.2 \%$ for the group 2). Besides, a canonical correlation coefficient of 0.87 and Wilks' Lambda of 0.14 supported the high fitness of the estimated discriminant function. Therefore, in a sense of distinguishing the AEWs in group 1 from the AEWs in group 2, according to the coefficients (Table 6), OJT such as "practice of delivering information to farmers under close supervision of AEO" was a remarkable determinant.

A Case of Skill on Working with Group: Out of 90 cases used in the discriminant analysis, 46 cases belonged to the group 1 (namely the low skill level group) and 44 cases to the group 2 (namely the high skill level group). The mean discriminant score

(centroid) for the group 1 (-2.45) was significantly different that for the group 2 (2.56). According to the estimated discriminant function, an overall correct classification rate was $94.4 \%(95.7 \%$ for the group 1 and $93.2 \%$ for the group 2). Besides, a canonical

Table 5. Comparison of OJT practices by AEWs' group 1 and AEWs' group 2

\begin{tabular}{|c|c|c|c|}
\hline \multirow[t]{2}{*}{ OJT Practice } & \multicolumn{2}{|c|}{$\begin{array}{l}\text { Number of AEWs according } \\
\text { to OJT practice }\end{array}$} & \multirow{2}{*}{$\chi^{2}$-value } \\
\hline & $\begin{array}{l}\text { AEWs' } \\
\text { group } 1^{\text {a }}\end{array}$ & $\begin{array}{l}\text { AEWs' } \\
\text { group } 2^{\text {b }}\end{array}$ & \\
\hline \multicolumn{4}{|l|}{ Working with Group } \\
\hline Forming new group under close supervision of AEO & $36(78 \%)^{\mathrm{c}}$ & $44(100 \%)$ & $-3.46 * * *$ \\
\hline $\begin{array}{l}\text { Try to form sub-group without supervision of officer and bring the finished } \\
\text { tasks to AEO }\end{array}$ & $6(13 \%)$ & $39(89 \%)$ & $-10.83 * * *$ \\
\hline Practice of delivering information to farmers under close supervision of AEO & $2(<1 \%)$ & $41(92 \%)$ & $-18.21 * * *$ \\
\hline Practice of selecting group leader under close supervision of AEO & $4(<1 \%)$ & $40(91 \%)$ & $-13.55 * * *$ \\
\hline \multicolumn{4}{|l|}{ Organizing and Running a Demonstration } \\
\hline Motivate farmers in presence of AEO or skilled AEW & $4(<1 \%)$ & $38(85 \%)$ & $-10.88 * * *$ \\
\hline $\begin{array}{l}\text { Selecting demonstration site and appropriate technology with close } \\
\text { supervision of AEO }\end{array}$ & $23(51 \%)$ & $40(89 \%)$ & $-4.24 * * *$ \\
\hline $\begin{array}{l}\text { Try to conduct demonstration without supervision of AEO and seeking } \\
\text { advice from AEO }\end{array}$ & $3(<1 \%)$ & $44(98 \%)$ & $-24.81 * * *$ \\
\hline Record all the activities of demonstration and seeking advice from AEO & 1 & $44(90 \%)$ & $-30.41 * * *$ \\
\hline \multicolumn{4}{|l|}{ Assessing Farmers' Problems } \\
\hline Assessing farmers' problems with close supervision of AEO & $48(100 \%)$ & $42(100 \%)$ & 1.16 \\
\hline $\begin{array}{l}\text { Assessing farmers' problems without supervision of officers and finally } \\
\text { seeking advice from the AEO }\end{array}$ & $3(<1 \%)$ & $42(100 \%)$ & $74.84 * * *$ \\
\hline $\begin{array}{l}\text { Discuss with AEO or skilled AEW about the problems in assessing farmers' } \\
\text { problems }\end{array}$ & 0 & $42(100 \%)$ & $90 * * *$ \\
\hline \multicolumn{4}{|l|}{ Work Planning } \\
\hline Preparing work plan with close supervision of AEO & $37(86 \%)$ & $47(100 \%)$ & $7.03 * * *$ \\
\hline $\begin{array}{l}\text { Try to make work plan without supervision of AEO and bring the finished } \\
\text { task to AEO }\end{array}$ & 0 & $47(100 \%)$ & $90 * * *$ \\
\hline Discuss with AEO or skilled AEW about the problems of work planning & $7(16 \%)$ & $42(89 \%)$ & $48.36 * * *$ \\
\hline
\end{tabular}

Note. ${ }^{a} \mathrm{AEWs}$ ' group 1: AEWs who have less than the average skill level; ${ }^{\mathrm{b}} \mathrm{AEWs}$ ' group 2: AEWs who have higher than the average skill level;

${ }^{c}$ Values in the parenthesis are percentages of AEWs.

Source:Authors'survey(2006) 
Table 6. Result of Discriminant Analysis on Contributing OJT for AEWs Extension Skills

\begin{tabular}{|c|c|c|c|c|c|c|c|}
\hline \multirow{2}{*}{$\begin{array}{ll}\text { Practice of OJT } \\
\text { Working with Group }\end{array}$} & \multirow[t]{2}{*}{$\mathrm{b}$} & \multirow[t]{2}{*}{$\begin{array}{l}\text { Eigen } \\
\text { value }\end{array}$} & \multirow[t]{2}{*}{ Rc } & \multirow[t]{2}{*}{$\begin{array}{l}\text { Wilks' } \\
\text { Lambda }\end{array}$} & \multirow[t]{2}{*}{$\begin{array}{c}\mathrm{p}- \\
\text { value }\end{array}$} & \multicolumn{2}{|c|}{$\begin{array}{l}\text { Group } \\
\text { centroids }\end{array}$} \\
\hline & & & & & & $\mathrm{G} 1^{\mathrm{a}}$ & $\mathrm{G} 2^{\mathrm{b}}$ \\
\hline Forming new group under close supervision of AEO & 0024 & & & & & & \\
\hline $\begin{array}{l}\text { Try to form sub-group without supervision of officer and } \\
\text { bring the finished tasks to AEO }\end{array}$ & 0.515 & & & & & & \\
\hline $\begin{array}{l}\text { Practice of delivering information to farmers under close } \\
\text { supervision of AEO }\end{array}$ & 0.710 & 6.41 & 0.87 & 0.14 & $<0.10$ & -2.45 & 2.56 \\
\hline $\begin{array}{l}\text { Practice of selecting group leader under close supervision of } \\
\text { AEO }\end{array}$ & 0.381 & & & & & & \\
\hline \multicolumn{8}{|l|}{ Organizing and Running a Demonstration } \\
\hline Motivate farmers in presence of AEO or skilled AEW & 0.138 & & & & & & \\
\hline $\begin{array}{l}\text { Selecting demonstration site and appropriate technology } \\
\text { with close supervision of AEO }\end{array}$ & 0.000 & & & & & & \\
\hline $\begin{array}{l}\text { Try to conduct demonstration without supervision of AEO } \\
\text { and seeking advice from AEO }\end{array}$ & 0.704 & 12.92 & 0.92 & 0.07 & $<0.10$ & -3.55 & 3.55 \\
\hline $\begin{array}{l}\text { Record all the activities of demonstration and seeking advice } \\
\text { from the AEO }\end{array}$ & 0.436 & & & & & & \\
\hline \multicolumn{8}{|l|}{ Assessing Farmers' Problems } \\
\hline Assessing farmers' problems with close supervision of AEO & 0.000 & & & & & & \\
\hline $\begin{array}{l}\text { Assessing farmers' problems without supervision of officers } \\
\text { and finally seeking advice from the AEO }\end{array}$ & 1 & 7 & 0.87 & 0.13 & $<0.10$ & -2.45 & 2.80 \\
\hline $\begin{array}{l}\text { Discuss with AEO or skilled AEW about the problems in } \\
\text { assessing farmers' problems }\end{array}$ & 0.000 & & & & & & \\
\hline \multicolumn{8}{|l|}{ Work Planning } \\
\hline Preparing work plan with close supervision of AEO & 0.264 & & & & & & \\
\hline $\begin{array}{l}\text { Try to make work plan without supervision of AEO and } \\
\text { bring the finished task to AEO }\end{array}$ & 0.000 & 1.25 & 0.56 & 0.45 & $<0.10$ & -1.55 & 1.06 \\
\hline $\begin{array}{l}\text { Discuss with AEO or skilled AEW about the problems of } \\
\text { work planning }\end{array}$ & 0.965 & & & & & & \\
\hline
\end{tabular}

correlation coefficient of 0.87 and Wilks' Lambda of 0.14 supported the high fitness of the estimated discriminant function. Therefore, in a sense of distinguishing the AEWs in group 1 from the AEWs in group 2, according to the coefficients (Table 6), OJT such as "practice of delivering information to farmers under close supervision of AEO" was a remarkable determinant.

A Case of Skill on Organizing and Running a Demonstration: Out of 90 cases, 45 cases belonged to the group 1 (namely the low skill level group) and 45 cases to the group 2 (namely the high skill level group).

The mean discriminant score (centroid) for group 1 (3.55) was significantly different from that for the group 2 (3.55). The discriminant function resulted in an overall correct classification rate of $97.8 \%$ (97.8\% for the group 1 and $97.8 \%$ for the group 2). In addition, low value of Wilks' Lambda (0.07) and high canonical correlation (0.92) indicated the high fitness of the estimated discriminant function. As a result, in a sense of distinguishing the AEWs in group 1 from the AEWs in group 2, according to the coefficients (Table 6), OJT such as "try to conduct demonstration without supervision of AEO and seeking advice from AEO" was a significant determinant.

A Case of Skill on Assessing Farmers' Problems: Out of 90 cases, 48 cases belonged to the group 1 (namely the low skill level group) and 42 cases to the group 2 (namely the high skill level group). The mean discriminant score (centroid) for the group $1(-2.45)$ was significantly different from that for the group 2 (2.80). The discriminant function resulted in an overall correct classification rate of $96.7 \%$. AEWs in group 1 were correctly classified $93.8 \%$ of the time whereas AEWs in group 2 were correctly classified $100 \%$ of the time. Besides, Wilks' Lambda of 0.13 and a canonical correlation coefficient of 0.87 supported the high fitness 
of the estimated discriminant function. The procedure resulted in the selection of one discriminating OJT from the three included in the analysis. According to the coefficients (Table 6) OJT such as "assessing farmers' problems without supervision of officers and finally seeking advice from the AEO" was remarkable determinant for distinguishing group $1 \mathrm{AEWs}$ from the group 2 AEWs.

A Case of Skill on Work Planning: All of the cases (90) were used in the discriminant analysis. Of those, 43 cases belonged to the group 1 (namely the low skill level group) and 47 cases to the group 2 (namely the high skill level group). The mean discriminant score (centroid) for the group 1(-1.55) was significantly different from that for the group 2 (1.06). The function resulted in an overall correct classification rate of $86.7 \%$. AEWs in group 1 were correctly classified $83.7 \%$ of the time whereas AEWs in group 2 were correctly classified $89.4 \%$ of the time. Besides, Wilks' Lambda of 0.45 and a canonical correlation coefficient of 0.56 supported the high fitness of the estimated discriminant function. The most distinguishing OJT between AEWs in group 1 and AEWs in group 2 can be determined by examining the discriminant function coefficients (Table 6). Hence, according to the coefficients, OJT such as "discuss with AEO or skilled AEW about the problems of work planning" was a significant determinant for distinguishing the AEWs in group 1 from the AEWs in group 2.

\section{CONCLUSIONS}

Regarding all of the four extension skills, most of the Off-JTs' attendance significantly differed between the AEWs in group 1 (namely the low skill level group) and AEWs in group 2 (namely the high skill level group). Except one Off-JT on developing group dynamics all the others Off-JTs were important contributing factors to the AEWs' skill on working with group. This was because most of the AEWs could not understand the training on group dynamics due to lack of basic academic knowledge. Less than half of the OffJTs were important contributing factors to the AEWs' skill on organizing and running a demonstration, problem identification, and planning. On the other hand, almost all of the high skill level AEWs (group 2) were practiced OJT with intension to develop their skill levels on all of the four extension skills. However, the OJT that practiced by the low skill level AEWs (group
1) was very mush limited. Practice of OJT under the close supervision of officer was found important contributing factor to the AEWs' skill on working with group. Practice of OJT without supervision of officer was the most contributing factor to AEWs' skill on organizing and running demonstration, assessing farmers' problems. Moreover, OJT such as discussion with officers/skilled AEWs about work planning was important contributing factor to AEWs' skill on planning. Thus, based on the findings the following recommendations are offered:

1. The DAE should make strong look on effective Off-JT for developing AEWs' extension skills. Besides, its need to elicit the reasons behind the less effectiveness of some Off-JTs.

2. It needs to ensure an instructor for getting help at the time of practicing OJT. In that case, the DAE should plan extension activities for the AEWs which can provides opportunities of getting help from skilled colleagues at the time of practicing OJT.

The findings of the study indicate that some OffJTs are less effective for developing AEWs' extension skills. On the other hand, lack of OJT practices is one of the major obstacles for developing AEWs' extension skills on providing need-based agricultural extension services. Thus, it can be concluded that the results of this study could have some implications in developing AEWs' training program in Bangladesh. Besides, the findings may also be used as a basis and guide for providing effective training to the Agricultural Extension Personnel in other developing nations.

\section{ACKNOWLEDGEMENTS}

The authors gratefully acknowledge the Agricultural Officers and Agricultural Extension Workers in the study area for providing all out support in data collection activities.

\section{REFERENCES}

1. Ahmad, R. 2002. Constraint in Implementing New Agricultural Extension Policy (NAEP) in Bangladesh. Proceeding of the National Workshop on "Implementation of the New Agricultural Extension Policy: Achievement and Constraints". January 26-28. 2002. 
2. Annual Training Plan 2002-2003. Department of Agricultural Extension. Dhaka, Bangladesh.

3. Ajayi, M. T. (2001). A comparison of the effectiveness of on-campus and off-campus training courses for agricultural staff at the international institute of tropical agricultures (IITA). Journal of International Agricultural and Extension Education, 8(3), 41-47.

4. Babu, A.R. and Sinha, B.P. 1979. Information Gap between Extension Personnel and Farmers with regards to Modern Rice Technology. Indian Journal of Extension Education, 15 (3\& 4): 52-60.

5. BBS. 2002. Bangladesh Bureau of Statistics: Government of the People's Republic of Bangladesh.

6. Charles, K. R. 1990. Evaluating training: An experimental approach. Training \& Management development Methods, 4 (1), 17-29.

7. DAE. 1999. Agricultural Extension Manual. Ministry of Agriculture: Government of the People's Republic of Bangladesh.

8. DAE. 2003. Annual report. Department of Agricultural Extension, Kishorganj: Government of the People's Republic of Bangladesh.

9. DAE. 2002. Strategic Plan for 2002-2006. Department of Agricultural Extension. Dhaka, Bangladesh.

10. Halim, A. 1991. Development and management of human resources in agricultural extension. Bangladesh Journal of Extension Education, 6(1\&2), 89-98.

11. Haider, M. R., Halim,A, \& Islam M.M. 2001. Adoption of Improved Aman Rice Technologies. Bangladesh Journal of Extension Education, 13(1\&2), 83-89.
12. Hoque, M.J., \& Usami, K. 2007. Effectiveness of Agricultural Extension Training Courses for Block Supervisors at the Department of Agricultural Extension in Bangladesh. Journal of International Agricultural and Extension Education, 14(2), 5159.

13. Hoque, M.J., \& Usami, K. 2007. Effects of Agricultural Extension Workers' Perceptions of Off-the-Job Training and On-the-Job Training to the Development of Their Skills. American Journal of Agricultural and Biological Sciences, 2(3), 184190.

14. Kashem, M.A., Hossain, M.A., \& Islam, M.S. 2001. Factors Responsible for Determining Communication Behaviour of the Block Supervisors. Bangladesh Journal of Extension Education, 13(1\&2), 137-142.

15. Karim, A. S. M. Z., \& Mahboob, S. G. 1991. Extent of job performance of the subject matter officers working in the department of agricultural extension in Bangladesh. Bangladesh Journal of Extension Education, 6(1\&2), 13-26.

16. Koike, K. \& Inoki, T. 1990. Skill Formation in Japan and Southeast Asia. University of Tokyo Press.

17. Reyna, R., \& Bruening, T. 1996. Agricultural extension issues: Perception of Bangladesh T\&V extension personnel. Journal of International Agricultural and Extension Education, 3(1), 53-62. 